\title{
ARTIGOS
}

\section{Formação de professores na educação profissional: uma análise sobre a dimensão pedagógica}

RESUMO: O artigo examina as perspectivas de formação pedagógica de professores, no âmbito da educação profissional no Brasil, olhando-as a partir de resultados de estudos. A investigação consiste em uma análise qualitativa e interpretativa, baseada em uma análise de conteúdo, sobre dissertações e teses voltadas à temática 'formação pedagógica de professores na educação profissional', produzidas no período compreendido entre 2005-2015. Este recorte temporal foi estabelecido tendo em vista a expansão dos estudos sobre esta temática, concomitante a expansão da própria educação profissional em nosso país. Os dados foram analisados sob a luz das perspectivas teóricas relacionadas à profissionalidade e constituição docente, esboçadas por Maurice Tardif, José Contreras e José Gimeno Sacristán. Os resultados evidenciaram perspectivas distintas de formação pedagógica docente, das quais duas são discutidas neste artigo: formação profissional docente que prioriza a articulação entre teoria e prática e a complementaridade entre disciplinas e dimensões formativas, na medida em que os docentes reconhecem a importância e valorizam a dimensão pedagógica da formação para a concretização da prática profissional; e formação profissional docente que se concretiza mediante a constituição profissional do professor e a prática pedagógica, visto que para um grupo de professores desta modalidade de educação o conhecimento prático assume centralidade na constituição da profissionalidade docente.

PALAVRAS-CHAVE: Formação de professores. Educação Profissional. Formação pedagógica. Profissionalidade.

1 Mestre em Educação pelo Programa de Pós-graduação em Educação da Universidade Federal da Fronteira Sul (UFFS). Docente na Universidade do Alto Vale do Rio do Peixe - UNIARP e do Instituto Federal Catarinense - IFC. E-mail: leandrohupalo.lh@gmail.com.

2 Doutora em Educação Matemática pela Universidade Estadual Paulista Júlio de Mesquita Filho (UNESP). Pós-doutorado em Didática da Matemática pelo Instituto de Educação da Universidade de Lisboa. Professora, nível associado, da Universidade Federal da Fronteira Sul (UFFS). Docente do Programa de Pós-graduação em Educação da UFFS. E-mail: adrianarichit@gmail.com. Endereço para correspondência: Avenida Sete de Setembro, 222, Apto 92. Centro, Erechim, RS, Brasil. 


\title{
autêntica
}

DOI https://doi.org/10.31639/rbpfp.v\%vi\%i.210

\section{Teachers' education in the professional education: an analysis about the pedagogical dimension}

\begin{abstract}
The paper analyses the perspectives about teacher's pedagogical education of the professional education in the Brazil from the research results. The investigation consist in a qualitative and interpretative analyses based in a content analyse of dissertation and thesis dedicated to theme 'teacher pedagogical education in the professional education', which were developed in the period between 2005 and 2015. This temporal cut was established because in this period there was been a studies' expansion about this theme in our country. Dates were analysed under the theoretical perspectives related to professionalism and teacher constitution outlined by Maurice Tardif, José Contreras and José Gimeno Sacristán. Outcomes revealed different perspectives about teachers' pedagogical education, two of them are discussed in this paper: teacher professional education that focus about the combination of theory and practice and a complementarity between curricular disciplines and teachers' education dimensions; and teachers' professional education which is realized through the teacher professional constitution and the pedagogical practice.
\end{abstract}

KEYWORDS: Teacher's education. Professional Education. Pedagogical. Professionalism. 


\section{autêntica}

DOI https://doi.org/10.31639/rbpfp.v\%vi\%i.210

\section{INTRODUÇÃO}

A formação pedagógica do professor da educação profissional constitui-se em dimensão prioritária no cenário nacional desde a aprovação da Lei de Diretrizes e Bases da Educação Nacional - LDB, Lei n. 9.394 de 20 de dezembro de 1996, no âmbito da qual são estabelecidas as dimensões contempladas por essa modalidade de educação. Segundo o Artigo 39 da LDB, "a educação profissional e tecnológica3, no cumprimento dos objetivos da educação nacional, integra-se aos diferentes níveis e modalidades de educação e as dimensões do trabalho, da ciência e da tecnologia" (BRASIL, 1996, p. 261).

De acordo com as diretrizes legais, a educação profissional objetiva, sobretudo, elevar a condição intelectual do ser humano mediante uma formação que ultrapasse o tradicional repertório de suas funções laborais (BRASIL, 2008). Para alcançar a formação profissional e intelectual desejada para o estudante, a formação do professor dessa modalidade de educação precisa incluir, entre outras, a dimensão pedagógica (BRASIL, 2012), por meio da qual possa promover uma prática profissional coerente e comprometida, na qual estejam imbricados conhecimentos específicos, profissionais, disciplinares, curriculares, científicos e experienciais.

Por outro lado, embora as pesquisas sobre a formação docente no Brasil tenham avançado nas últimas décadas, ainda são escassos os estudos sobre a formação de professores da educação profissional e tecnológica. Tal carência é evidenciada em Pena (2011) ao mostrar que em um levantamento realizado em diferentes bancos de dados - Banco de Teses da Capes, anais da ANPEd referentes ao GT 8 - Formação de professores, Revista Brasileira de Educação e Cadernos de Pesquisa, Educação e Sociedade -, utilizando os descritores de busca "formação de professores para a educação profissional", "formação de professores para o ensino técnico" e "professor do ensino técnico", foram encontradas apenas duas pesquisas com esse foco, ambas dissertações de mestrado desenvolvidas entre 2000 e 2009.

A carência de pesquisas na área de formação docente na educação profissional evidencia que, embora tal modalidade de educação tenha crescido consideravelmente no país nos últimos anos, a formação docente não se apresenta como prioridade nas políticas públicas, resultando na concepção de que o conhecimento técnico e específico da área de atuação ainda é considerado basilar e suficiente para a realização da docência.

No entanto, estudos sobre a educação profissional, tais como Araújo (2014), Machado (2011), Urbanetz (2011), Barbacovi (2011), Santos (2008) e Kuenzer (2007), revelam, entre outras coisas, que a formação inicial dos professores que atuam nessa modalidade de educação tem sido predominantemente específica e de caráter técnico, principalmente nas áreas relacionadas à tecnologia. Predominam nas instituições de educação profissional, atuando na docência em cursos profissionalizantes, professores com formação meramente técnica e experiência prática, sem qualquer formação pedagógica.

Assumindo a importância e a necessidade de se priorizar a formação pedagógica de professores que atuam na educação profissional e, principalmente, a problemática relacionada a esta dimensão da formação docente, debruçamo-nos em examinar as perspectivas de formação pedagógica de professores da educação profissional evidenciadas em estudos com foco nesta temática.

A pesquisa baseou-se em um estudo do tipo bibliográfico, que consistiu na análise de dez dissertações e teses concluídas recentemente em programas de pós-graduação brasileiros, com foco na educação profissional, a 


\section{autêntica}

DOI https://doi.org/10.31639/rbpfp.v\%vi\%i.210

partir da qual buscamos responder a seguinte interrogação: quais são as principais perspectivas de formação pedagógica de professores, subjacentes às pesquisas com foco na educação profissional desenvolvidas no Brasil entre os anos de 2005 e 2015? Este recorte temporal foi estabelecido tendo em vista a expansão dos estudos sobre esta temática na referida década, concomitante à expansão da própria educação profissional em nosso país no mesmo período. E a delimitação da temática deu-se mediante a necessidade de examinar o modo como esta dimensão da formação profissional docente (dimensão pedagógica), historicamente problemática nesta modalidade educativa, vem sendo concebida e concretizada em face a esta expansão, pois na educação profissional recrutam-se professores "fiando-se apenas em formação específica e experiência prática, crendo que a constituição da docência se dará pelo autodidatismo" (MACHADO, 2011, p.691).

Mediante a análise dos resultados de dez trabalhos selecionados a partir de uma busca realizada no Banco de Teses e Dissertações da Coordenação de Aperfeiçoamento de Pessoal de Nível Superior - CAPES, Biblioteca Digital Brasileira de Teses - BDBT e Dissertações do Instituto Brasileiro de Informação em Ciência eTecnologia - IBICT, utilizando os descritores formação docente, educação profissional e formação de professores, identificamos algumas perspectivas de formação pedagógica predominantes nas instituições focadas, das quais duas são abordadas no presente texto: formação profissional docente que prioriza a articulação entre teoria e prática e a complementaridade entre disciplinas e dimensões formativas; e formação profissional docente que se concretiza mediante a constituição profissional do professor e a prática docente.

\section{PROFISSIONALIDADE E CONSTITUIÇÃO DOCENTE: PRESSUPOSTOS PARA A FORMAÇÃO DE PROFESSORES}

A profissão docente, segundo Castanho (2001), pressupõe características e conhecimentos que tornem o professor um profissional capaz de intervir de maneira ampla e coerente nas distintas situações do cotidiano escolar e que possa deixar marcas positivas no processo de formação dos estudantes. Explicitando as particularidades dos saberes profissionais docentes, Tardif (2013, p. 11) afirma que "o saber dos professores é o saber deles e está relacionado com a pessoa e a identidade deles com a sua experiência de vida e com a sua história profissional, com as suas relações com os alunos em sala de aula e com os outros atores escolares na escola".

Este entendimento encontra respaldo em Nóvoa (2009) ao afirmar que é impossível separar as dimensões pessoais e profissionais na profissão docente, de modo que ensinamos aquilo que somos e naquilo que somos se encontra muito do que ensinamos. Contudo, o processo de constituir-se professor é atravessado por crenças, concepções, ideologias, culturas profissionais e conhecimentos distintos que são desenvolvidos ao longo das diversas experiências profissionais e formativas vivenciadas pelo professor. Estes aspectos estão relacionados, entre outras coisas, ao desenvolvimento da profissionalidade docente.

O termo profissionalidade foi recentemente inserido no campo da educação, especificamente nas últimas décadas do século $X X$, em face à organização dos professores devido à institucionalização da necessidade de formação docente para exercer a atividade profissional, implicando na definição de um conjunto de saberes indispensáveis para sustentá-la (NÓVOA, 1995).

De acordo com Reis Monteiro (2008), o termo profissionalidade foi utilizado em educação pela primeira vez na Itália, nos anos 1960 e 1970, em face às lutas dos sindicatos contra a organização capitalista do trabalho. E a partir da década de 1970 passou a ser utilizado também na França e Reino Unido, disseminando-se ao redor do mundo a partir de então. Para este autor, a profissionalidade refere-se a 


\title{
autêntica
}

DOI https://doi.org/10.31639/rbpfp.v\%vi\%i.210

\begin{abstract}
um saber-comunicar-pedagogicamente, ou seja, com a legitimidade do direito à educação, competência nos saberes a comunicar e sobre comunicação e excelência pessoal. Os profissionais da educação podem, pois, ser considerados como profissionais do direito à educação e da comunicação pedagógica, oficialmente habilitados e socialmente investidos para o exercício da sua função (REIS MONTEIRO, 2008, p. 47)
\end{abstract}

Por seu lado Sacristán (1995, p. 65) entende profissionalidade como "afirmação do que é específico na ação docente, isto é, o conjunto de comportamentos, conhecimentos, destrezas, atitudes e valores que constituem a especificidade de ser professor." E Contreras (2012) refere-se à profissionalidade como o conjunto de qualidades da prática docente em função das exigências do trabalho educativo. Nesta perspectiva, debater profissionalidade docente significa "não só descrever o desempenho do trabalho de ensinar, mas também expressar valores e pretensões que se deseja alcançar e desenvolver nesta profissão" (CONTRERAS, 2012, p. 74). Complementarmente, Contreras (2013) apresenta três dimensões definidoras da profissionalidade docente: a obrigação moral e o compromisso de quem ensina para quem aprende; o compromisso com a comunidade e as relações sociais que aí se estabelecem; e a competência profissional, que combina habilidades, princípios e consciência de sentido.

Em uma perspectiva similiar Roldão (2005, p. 108) define o termo profissionalidade como um "conjunto de atributos, socialmente construídos, que permitem distinguir uma profissão de outros muitos tipos de atividades, igualmente relevante e valiosas." Acrescenta quatro elementos para definir o termo profissionalidade docente, baseados em análises das produções científicas de Nóvoa (2009), Sacristán (1995) e Dubar (2005): o reconhecimento social da especificidade da função; o saber específico indispensável à natureza de sua atividade; o poder de decisão baseado no controle e na autonomia sobre o exercício da atividade pedagógica; e o pertencimento a um grupo coletivo que compartilha, regula e defende o pleno exercício da profissão (ROLDÃO, 2005).

Em face aos entendimentos apresentados, a profissionalidade docente revela-se um processo que se desenvolve nas dimensões individual e coletiva e que se consolida no ambiente de trabalho e tem na atividade docente e nas relações com os pares a afirmação ou negação da profissão. Além disso, a profissionalidade docente é afetada pelas condições de trabalho, meios técnicos, respeito, remuneração, prestígio e atração exercida pela profissão, o que constitui um conjunto particular de condições características em um campo profissional específico, que em geral oscilam de acordo com condições de desenvolvimento econômico, social e histórico de cada contexto (ANDRE, 2013).

Popkewitz (1991) esclarece seu entendimento de profissionalismo focando na relação do que é ser professor e o conceito de profissão constituído mediante as condições de trabalho em que a prática profissional se concretiza. Para o autor, ser professor pressupõe compreender que o conceito de profissão é decorrente de uma situação social passível de alterações conforme as condições sociais e históricas do contexto em que tal conceito é instituído e legitimado. Este aspecto caracteriza o termo profissão como de difícil aproximação, oportunizando uma pluralidade de significações e implicando na falta de uma definição universal. Desta forma, a profissão docente deve ser entendida como um processo de emergência e diferenciação social de um determinado grupo ocupacional, que varia seu estatuto e redefine o conceito de profissão ao longo do período histórico.

Contudo, emergem no contexto da profissão docente entendimentos distintos sobre a especificidade da docência, sendo que alguns acabam por ser reducionistas na medida em que simplificam as dimensões 


\section{autêntica}

DOI https://doi.org/10.31639/rbpfp.v\%vi\%i.210

da formação e os conhecimentos necessários à prática. Sobre isto, Labaree (2000) afirma que se institui a ideia de que ensinar é muito simples, o que contribui significativamente para o desprestígio da profissão e, também, sugere que a profissão docente pode ser exercida sem a devida formação ou, de forma mais objetiva, por qualquer um que detenha boa vontade.

Além disso, Esquisani (2012) afirma que as expectativas coletivas sobre a docência giram em torno de uma tênue linha que separa profissionalismo e vocação: há uma relativa dificuldade histórica em definir se os professores são vocacionados e, consequentemente, profissionais ou se são profissionais e, consequentemente, vocacionados. Este aspecto tem contribuído para a descaracterização da profissão docente, a qual, por sua vez, implica na proletarização e na marginalização da classe.

Estudos de Tardif e Lessard (2013), Contreras (2012) e Tardif (2013) discutem este processo de descaracterização mediante a análise de elementos intrínsecos à profissão, tais como a divisão técnica do trabalho docente e a perda da autonomia dos professores quanto à sua prática pedagógica e participação efetiva nas decisões que afetam a carreira profissional. A consequência deste processo é a marginalização do trabalho docente pela sociedade, que passa a considerar o professor como um mero executor de tarefas, um simples proletário da educação (CONTERAS, 2012).

Sumarizando, o conceito de profissionalidade sugere, deste modo, uma compreensão da docência em sua complexidade e numa perspectiva relacional entre os indivíduos, não deixando de considerar os espaços sociais, nos quais os professores efetivam seu trabalho, bem como os valores e desejos intrínsecos no desenvolvimento de profissão. Assim, a noção de profissionalidade docente é complexa e encontra-se em processo de constituição conceitual dentro da sociologia das profissões, conforme defendem Ludke e André (1996), ao afirmarem que a discussão do termo encontra-se em plena estruturação conceitual, não havendo consenso entre pesquisadores, o que torna mais complexa a definição do conceito.

No que concerne à educação profissional, segundo Hobold (2004), quando o professor ingressa na profissão, este não está desprovido de conhecimentos de outrora e nem dispensado de aprendizagens futuras. A troca de experiências pode ser ressignificada pelos professores com o objetivo de construir e refletir sobre sua prática pedagógica. Desta forma evidencia-se que o processo de formação do professor da educação profissional é uma peça-chave para a consolidação de uma escola emancipadora e socialmente transformadora, sobretudo nesta modalidade educativa que está diretamente ligada às relações de trabalho.

Em outras palavras, à docência na educação profissional necessita de profissionais com formação pedagógica que Ihes possibilite práticas de sala de aula comprometidas com a formação do estudante, e não apenas com a apropriação e o desenvolvimento de habilidades e competências específicas de uma determinada área profissional. Para Nóvoa (2009) a formação docente, pautada no conceito de profissionalidade e na pessoalidade do professor, deve compreender cinco propostas genéricas que, devidamente contextualizadas, podem inspirar uma renovação dos programas e das práticas formativas. São elas: o conhecimento, a cultura profissional, o tato pedagógico, o trabalho em equipe e o compromisso social. 


\section{autêntica}

DOI https://doi.org/10.31639/rbpfp.v\%vi\%i.210

Por fim, no contexto das discussões sobre o processo de formação docente, a questão da profissionalidade é fundamental, pois é parte inerente ao desenvolvimento e a constituição do professor, principalmente na educação profissional. Para tanto, o seu compromisso com a proposta da educação é elemento essencial para a concretização de uma educação comprometida com uma formação mais abrangente dos alunos.

\section{DELINEAMENTOS METODOLÓGICOS DO ESTUDO}

A análise esboçada neste texto, de natureza qualitativa e interpretativa (ERICKSON, 1986) e baseada em uma análise de conteúdo (BARDIN, 1977), constitui-se em um recorte de uma pesquisa de mestrado, desenvolvida em torno do objetivo de evidenciar e compreender as perspectivas de formação pedagógica de professores subjacentes a um conjunto de dez dissertações e teses, defendidas entre 2005-2015, com foco na educação profissional no Brasil.

A análise interpretativa, segundo Erickson (1986), consiste em um processo de interpretação, por parte do pesquisador, dos significados atribuídos pelas pessoas a um dado evento ou fenômeno em estudo, considerando-se as especificidades culturais e sociais do meio em que essa pessoa está inserida e os diversos fatores externos e internos que interferem nesse evento/fenômeno. Esta abordagem ocupa um reconhecido lugar entre as várias possibilidades de se estudar os fenômenos que envolvem pessoas e as relações sociais que são estabelecidas nos mais variados ambientes.

A relevância da temática focada no estudo prende-se a aspectos diversos, dentre ele a expansão da educação profissional no Brasil a partir dos anos 2000, que elevou consideravelmente a demanda por professores para atuar nesta modalidade de educação, que é historicamente marcada pela presença predominante de profissionais com formação em áreas profissionais técnicas e com pouca ou nenhuma formação de natureza pedagógica. E em face a demanda por docentes para atuar nestas instituições um novo fenômeno se revelou: a promoção de processos de formação pedagógica de caráter emergencial.

Neste sentido, interessamo-nos em investigar, a partir de pesquisas consolidadas sobre esta temática, as perspectivas de formação pedagógica que têm predominado nas ações promovidas e examinadas no âmbito dos estudos realizados no período especificado.

Assim, procedemos uma busca no Banco de Teses e Dissertações da CAPES, Biblioteca Digital Brasileira de Teses e Dissertações do IBICT, utilizando os descritores de busca: formação docente, educação profissional e formação de professores. Mediante um quantitativo de 109 trabalhos (teses e dissertações), identificados a partir da busca, procedemos a leitura dos resumos dos trabalhos visando identificar estudos que contemplavam, em suas discussões, a dimensão pedagógica das ações de formação docente nesta modalidade educativa. Este procedimento levou-nos a identificar dez trabalhos com foco específico em nosso objeto de investigação, dos quais seis dissertações e quatro teses. 


\section{autêntica}

DOI https://doi.org/10.31639/rbpfp.v\%vi\%i.210

QUADRO 1: DISSERTAÇÕES E TESES ANALISADAS

\begin{tabular}{|c|c|c|}
\hline Autor & Título do trabalho & Natureza \\
\hline Ogliari (2006) & $\begin{array}{c}\text { Concepção de formação inicial de professores para a educação } \\
\text { profissional de nível médio: Um aspecto da história da educação } \\
\text { no estado do Paraná }\end{array}$ & Dissertação \\
\hline $\begin{array}{l}\text { Barbacovi } \\
\text { (2011) }\end{array}$ & $\begin{array}{c}\text { O professor da educação profissional e a conectividade orgânica } \\
\text { entre formação e pratica docente: um estudo sobre o IFET Sudeste } \\
\text { de Minas Gerais }\end{array}$ & Tese \\
\hline Martins (2011) & Trajetórias de constituição da docência na educação profissional & Dissertação \\
\hline Oliveira (2011) & $\begin{array}{l}\text { Formação continuada de professores e o desenvolvimento de } \\
\text { currículos integrados na educação profissional e tecnológica }\end{array}$ & Dissertação \\
\hline $\begin{array}{l}\text { Urbanetz } \\
\text { (2011) }\end{array}$ & A constituição do docente para a educação profissional & Tese \\
\hline $\begin{array}{l}\text { Costa } \\
(2012)\end{array}$ & $\begin{array}{l}\text { Políticas de formação de professores para a educação profissional } \\
\text { e tecnológica: cenários contemporâneos }\end{array}$ & Tese \\
\hline Lima (2012) & $\begin{array}{l}\text { A formação de professores nos institutos federais de educação, } \\
\text { ciência e tecnologia: um estudo da concepção política }\end{array}$ & Dissertação \\
\hline Santos (2013) & $\begin{array}{c}\text { A autoformação docente no ensino técnico-profissional na interface } \\
\text { com a prática pedagógica: significados e potencialidades }\end{array}$ & Dissertação \\
\hline Araújo (2014) & $\begin{array}{c}\text { A formação docente para a educação profissional e tecnológica } \\
\text { no IFNMG - Campus Januária }\end{array}$ & Dissertação \\
\hline Pinto (2014) & $\begin{array}{c}\text { A constituição do professor pelo trabalho docente na educação } \\
\text { profissional: o caso do IFMT - Campus Cuiabá - } \\
\text { Octayde Jorge da Silva }\end{array}$ & Tese \\
\hline
\end{tabular}

Fonte: Elaborado pelos autores.

Após a delimitação deste conjunto de trabalhos, procedemos uma cuidadosa análise sobre as perspectivas de formação pedagógica de professores apontadas como necessárias e/ou adequadas para a concretização da docência no âmbito da educação profissional. Nossa análise orientou-se pelas seguintes questões: Quais aspectos/saberes são considerados necessários à docência na educação profissional? Quais são os principais obstáculos a realização do ensino na educação profissional? Quais aspectos deveram ser enfatizados nas ações de formação pedagógica ofertadas aos profissionais desta modalidade de ensino?

A partir da análise realizada identificamos um conjunto de evidências empíricas que apontam para algumas perspectivas de formação pedagógica de professores que atuam na educação profissional, das quais abordamos aqui as temáticas relacionadas à formação profissional docente que prioriza a articulação entre teoria e prática e a complementaridade entre disciplinas e dimensões formativas e; à formação profissional docente que se concretiza mediante a constituição profissional do professor e a prática pedagógica. 


\section{autêntica}

DOI https://doi.org/10.31639/rbpfp.v\%vi\%i.210

\section{SÍNTESE DAS DISSERTAÇÕES E TESES ANALISADAS}

A partir da leitura dos dez trabalhos elaboramos uma síntese de cada um, buscando explicitar os principais elementos conceituais, teóricos, metodológicos e culturais a eles subjacentes, em face aos quais foram evidenciadas as perspectivas de formação pedagógica, isto é, as categorias de análise discutidas na próxima seção deste artigo. Nesta seção nos dedicamos a apresentar as sínteses de cada trabalho.

Ogliari (2006) investigou a trajetória de formação inicial em licenciatura dos professores do Estado do Paraná que atuam no nível profissionalizante, examinando a Lei 5.692/71 e a Lei 9.394/96, e considerando os contextos sociais e políticos de cada época. Para tanto, analisou os princípios norteadores da formação docente do professor de educação profissional presentes nas legislações citadas, bem como discutiu a relação entre a formação do professor e a formação profissional do aluno desta modalidade educativa. A partir do depoimento de professores que atuavam na educação profissional em três instituições do referido Estado, os quais possuíam formação inicial em licenciatura, o autor identificou e problematizou as dificuldades encontradas no que se refere à formação docente, bem como as concepções de formação de professores presentes na educação profissional. Como resultados destaca que os professores da educação profissional do Estado do Paraná, particularmente nas instituições investigadas, desconhecem as legislações vigentes sobre a formação docente e a esta modalidade, embora considerem como relevante o conhecimento das leis que regulamentam a profissão docente. E este aspecto evidencia, portanto, falta de clareza sobre as finalidades e propósitos da educação profissional, bem como sobre seus princípios reguladores. Aponta, ainda, para a existência de uma fragilidade na formação inicial dos professores ao privilegiar a preparação para o trabalho docente apenas para a educação básica geral e sugere a inserção, nos cursos de licenciatura, de percursos formativos relacionados à educação profissional, visto que uma parcela de professores também atua nesta modalidade.

Barbacovi (2011) investigou a formação de professores da educação profissional no Brasil, com foco nos docentes do Instituto Federal de Educação, Ciência e Tecnologia - IFET Sudeste de Minas Gerais. A partir de um trabalho composto por análise documental, questionário e entrevistas realizadas com professores daquela instituição, o autor identificou o perfil acadêmico e profissional dos docentes participantes da pesquisa. Mediante o perfil profissional encontrado, o estudo revelou que as marcas do processo de constituição da formação docente são predominantes na prática profissional cotidiana dos professores em sala de aula e, ainda, que os profissionais da referida instituição não atribuem importância significativa à formação pedagógica inicial ou continuada. Como resultado aponta que o elemento que realmente interfere na constituição profissional do professor é a prática docente. Evidencia, em contrapartida, que a formação docente não tem relação com a prática cotidiana do ofício de professor, sugerindo, então, que não se trata de qualquer prática docente, mas sim de uma prática dotada de sentidos intrínsecos que sustenta o próprio processo de formação contínua do professor e que se desenvolve para além dos percursos formativos oferecidos pela instituição.

Oliveira (2011) investigou a prática docente no Instituto Federal de Santa Catarina - Campus Florianópolis (Continente) com o objetivo de identificar quais os sentidos que aqueles docentes atribuem à formação continuada de professores na prática pedagógica na educação profissional. Buscou, também, identificar as relações da prática reflexiva desenvolvida pelos professores e a constituição docente através de entrevistas e, a partir dos resultados obtidos, subsidiar formações docentes que possam atender as demandas profissionais levantadas em face ao estudo realizado. Os resultados do trabalho apontam para a necessidade de romper com a crença presente em tais instituições de que as formações de professores da educação profissional sejam caracterizadas por cursos pontuais e de cunho imediatista. Assumindo uma compreensão 


\section{autêntica}

DOI https://doi.org/10.31639/rbpfp.v\%vi\%i.210

contrária, a autora sugere a implementação de processos formativos consistentes e contínuos, que garantam a emancipação profissional e conduza o professor à autonomia docente. Conclui, assim, que a auto formação docente deve ser pautada na indissociabilidade entre teoria e prática.

Martins (2011) analisou a formação dos professores do Instituto Federal de Ensino, Ciência e Tecnologia de Santa Catarina - IFSC, Campus Florianópolis (Continente), focando os elementos relativos à constituição docente na educação profissional. Fundamentada numa pesquisa qualitativa, com base no estudo de caso de docentes da área da Nutrição daquela instituição, analisou as compreensões dos professores acerca dos elementos que subsidiam o processo de construção das práticas docentes e a constituição dos saberes docentes. Como resultados assinala, a partir dos depoimentos, que a constituição do professor se concretiza através do tempo e de suas experiências no exercício da docência. Em relação à formação docente, segundo os professores entrevistados, sua profissionalidade ancora-se nos modos de ser professor com os quais tiveram contato na formação inicial, particularmente, como nutricionistas antes de exercerem a docência. Aponta, por fim, a necessidade de desenvolver nos professores, por meio de percursos formativos na própria instituição de ensino, a dimensão didático-pedagógica da formação docente, visto que os entrevistados relataram dificuldades em entender o processo educativo e agir sobre ele, sobretudo nos primeiros anos de exercício da profissão docente.

Urbanetz (2011) investigou como se dá a formação do professor da educação profissional e a relação desta formação com o compromisso com a classe trabalhadora, delimitando o estudo aos docentes do curso de engenharia elétrica de uma determinada instituição de ensino profissional, em detrimento da intrínseca relação entre a referida área de conhecimento com o capitalismo industrial. A autora apoia seus argumentos na premissa de que a formação do professor se dá em duas dimensões: a constituição do professor pelo trabalho específico e pelo trabalho pedagógico, defendendo a ideia de que o docente precisa, sobretudo, conhecer o trabalho que vai ser ensinado aos alunos e apontando para a necessidade da vinculação da ação docente ao mundo do trabalho. Como conclusão evidencia que os professores entrevistados se constituem como docentes a partir da sua experiência de trabalho na engenharia: sua formação inicial, constituindo-se profissionalmente a partir do conhecimento tácito, articulado ao conhecimento científico adquirido na graduação. Assim, a sua competência, reconhecida pelos alunos, resulta da capacidade de, pela experiência, articular teoria e prática no âmbito dos processos de trabalho a serem ensinados. Destaca, ainda, que os docentes entrevistados, embora não possuam formação pedagógica sistematizada, se reconhecem como professores, pois suas práticas pautam-se em conhecimentos específicos e técnicos sobre sua área de atuação, os quais foram desenvolvidos na prática.

Lima (2012) examina a formação continuada de professores em Institutos Federais de Ciência e Tecnologia, focando as ações e diretrizes de formação docente presentes nestas instituições. Para tanto, investigou os pressupostos políticos e legais para a formação de professores destes Institutos, baseando-se em análise documental e realização de entrevistas com reitores das instituições de ensino pesquisadas. Os resultados apontam para um cenário permeado por contradições no que se refere à formação de professores nestas instituições, e que o processo de formação precisa ser reformulado, favorecendo a constituição de um profissional docente que intencione romper com a ordem do sistema capitalista vigente. Aponta, também, que uma das contradições diz respeito à formação gratuita e pública oferecida por estas instituições, porém, pragmática sob o ponto de vista da manutenção do atendimento das necessidades de um Estado neoliberal. A autora conclui, desta forma, que a concepção de formação de professores na educação profissional valoriza excessivamente os saberes técnicos em relação às necessidades humanas da sociedade contemporânea. 


\section{autêntica}

DOI https://doi.org/10.31639/rbpfp.v\%vi\%i.210

Costa (2012) analisou a carência de políticas públicas para a formação de professores da educação profissional. Mediante análises documentais e bibliográficas destacou a existência de programas formativos que facilitaram a inserção de profissionais sem a formação inicial em licenciaturas (não professores) na educação profissional, mas que acabaram não se transformando em políticas de governo. Destacou a intrínseca relação entre formação docente e o "aligeiramento" de tal formação em face da necessidade de docentes frente à expansão da educação profissional nos últimos anos. Na falta de uma concepção de formação docente para esta modalidade, a autora identificou que cada uma das instituições de ensino pesquisadas, sendo uma por região geográfica no Brasil, criou alternativas próprias para suprimir as carências de formação pedagógica dos docentes de educação profissional. Com isso, conclui que as diferentes propostas de formação docente são caracterizadas por controvérsias, incertezas, desafios, conflitos e obscuridade em relação à formação de professores da educação profissional, de modo que os processos formativos e educativos destas instituições se configuram em um movimento pendular, definidos pelo efeito dos cursos, ora marcados pela oferta de programas, ora pela oferta de licenciaturas.

Santos (2013) analisou a auto formação docente como processo de formação do professor pautado no investimento do próprio sujeito a partir da tomada de consciência de suas necessidades e desafios enquanto docente. Para tanto, investigou como ocorre o processo de auto formação de professores no contexto da educação profissional, baseando suas análises nos percursos formativos relatados por profissionais do Instituto Federal de Ensino, Ciência e Tecnologia do Piauí - Campus de Picos. Ancorado em uma abordagem qualitativa de pesquisa, estruturado em uma investigação bibliográfica e realização de entrevistas com docentes da Instituição, o estudo evidenciou a valorização do processo de auto formação docente como base enriquecedora do desenvolvimento pessoal e profissional do professor, valorizando a disposição para a mudança na ação reflexiva concernente à avaliação e a reinvenção de suas práticas formativas. Evidenciou, ainda, que os professores entrevistados valorizam conhecimentos específicos e pragmáticos devido à experiência laboral que tiveram em indústrias e empresas antes de ingressar na carreira docente. Embora não tenham formação inicial direcionada à docência, estes professores apresentam a consciência da incompletude de sua formação pedagógica e das fragilidades do trabalho docente que realizam, bem como da necessidade de ressignificação das suas práticas educativas. Por fim, aponta que os motivos que levam os professores a buscar alternativas diferenciadas para a melhoria do ensino ancoram-se, sobretudo, na necessidade de relacionar teoria e prática com vistas a promover uma formação para o mundo do trabalho. Sobre a auto formação, destaca que os docentes, de forma geral, reconhecem a importância da formação para a docência na educação profissional, e conclui que tal posição ratifica a ideia de que há uma consciência de que a ausência dessa formação pode impactar na ação de ensinar.

Araújo (2014) analisou a formação docente do professor de educação profissional do Instituto Federal de Ensino, Ciência e Tecnologia do Norte de Minas Gerais - IFNMG, Campus Januária. Com o objetivo de analisar como se dá a formação de professores para a educação profissional, o estudo se baseou numa perspectiva qualitativa, documental e bibliográfica, além de aplicação de questionário semiaberto aos professores da referida instituição, divididos em dois grupos: aqueles com formação acadêmica inicial em bacharel/engenharia ou tecnólogos e aqueles com formação inicial em licenciatura plena. Como resultados aponta a complexa e controversa relação entre a formação dos professores da educação profissional e a manutenção da pedagogia do capital e suas intencionalidades na formação dos alunos, sobretudo nos professores que não cursaram licenciatura. Complementa que a retórica oficial em questão tenta encobrir a formação do cidadão e do compromisso ético com a formação dos sujeitos em prol da manutenção e reprodução da ordem vigente. Destaca, também, que a formação do professor da educação profissional é fundamentada por concepções de uma agenda neoliberal, liderada por órgãos internacionais como o Banco Mundial, que preconiza uma 


\section{autêntica}

DOI https://doi.org/10.31639/rbpfp.v\%vi\%i.210

pedagogia pragmática em que a qualificação e o desenvolvimento de competências nos alunos definem a prática docente. Conclui, assim, que a profissão docente se mostra fragilizada e converge, sobretudo, para o enraizamento da cultura de que a formação pedagógica não se faz necessária para a docência, de modo que todos podem exercer tal função na modalidade de ensino profissional. Aponta, da mesma forma, a fragilidade nos processos de formação docente, destacando o aligeiramento de tais processos, relacionando-os com a lógica do capital e a racionalidade técnica presente na educação profissional.

Pinto (2014) focou seu estudo no trabalho docente do professor de educação profissional do Instituto Federal de Ensino, Ciência e Tecnologia do Mato Grosso - IFMT, Coronel Octayde Jorge da Silva, em Cuiabá, com o objetivo de analisar o trabalho docente na busca pela compreensão de como se dá a constituição docente a partir do fazer pedagógico. Seguindo uma abordagem qualitativa, de cunho materialista dialético, a pesquisa baseou-se em documentos institucionais e na análise de conteúdo mediante a realização de entrevistas com professores e diário de campo. Como resultados apontou a importância do trabalho docente como princípio educativo necessário ao rompimento do modo de pensar dominante em prol de uma docência que almeja, sobretudo, a superação do caráter funcionalista da educação profissional. Aponta, a partir das falas dos professores entrevistados, que a constituição docente naquela instituição se dá através do trabalho docente em detrimento da falta da continuidade de programas de formação. Destaca, também, que um dos reflexos da falta de formação docente com bases pedagógicas é a exclusão dos alunos que apresentam dificuldades para desenvolver a educação profissional. Por fim, demonstra que há dois tipos de modelos pedagógicos presentes no trabalho docente na educação profissional: o humanista e o taylorista/fordista, sendo este o predominante.

\section{PERSPECTIVAS DE FORMAÇÃO PEDAGÓGICA EVIDENCIADAS A PARTIR DOS ESTUDOS ANALISADOS}

Mediante nossa análise, duas importantes perspectivas de formação pedagógica de professores apontadas como sendo necessárias à docência na educação profissional foram evidenciadas. Em relação à temática formação profissional docente que prioriza a articulação entre teoria e prática e a complementaridade entre disciplinas e dimensões formativas, evidenciada nos estudos de Ogliari (2006), Oliveira (2011), Martins (2011), Urbanetz (2011), Costa (2012) e Pinto (2014), foram destacados aspectos relativos ao modo como os professores da educação profissional têm buscado articular teoria e prática na concretização da prática cotidiana de sala de aula, assim como promover a complementaridade entre a formação inicial e continuada docente. E esta complementaridade tem sido concretizada mediante o envolvimento dos professores em ações de formação contínua.

A respeito da integração entre as dimensões da formação geral e técnica da formação profissional, Ogliari (2006) ressalta que esta relação precisa ser concretizada, primeiramente, no âmbito da formação de professores.

$\mathrm{F}_{1}^{4}$ : Temos a consciência de que a integração, para se efetivar no ensino médio profissional, não depende apenas dos professores das disciplinas ditas comuns, mas também dos outros professores e de outros atores que atuam na escola [e, por isso, precisa ser efetivada também na formação do professores] (OGLIARI, 2006, p. 147).

O autor evidencia uma visão de formação profissional que se concretiza na interseção entre a dimensão formativa geral, a qual circunscreve conhecimentos pedagógicos e culturais da educação, e a dimensão

4 Adotamos a notação F1, F2...para identificar os fragmentos extraídos dos trabalhos analisados, os quais explicitam as perspectivas de formação, isto é, as categorias de análise discutidas no presente artigo seção. 


\section{autêntica}

DOI https://doi.org/10.31639/rbpfp.v\%vi\%i.210

técnica, que abarca os conhecimentos relativos a um campo de atuação profissional específico, estendendo esta compreensão para todos os campos de formação para o trabalho. Assim, sugere uma maior interação e integração entre os professores com formação em licenciatura e os professores bacharéis, assim como os demais membros da comunidade escolar, como forma de promover práticas de sala de aula adequadas ao desenvolvimento dos alunos.

Costa (2012) reforça a importância da complementaridade entre a formação técnica e a formação pedagógica, entendendo-as como componentes teórica e prática, considerando que esta complementaridade converge para uma educação politécnica.

$F_{2}$ : Esse entendimento tem como pressupostos os princípios de uma formação integrada, em que não haja uma formação propedêutica e uma formação técnica, mas, sim, uma formação politécnica (COSTA, 2012, p. 195).

$F_{3}:[\ldots]$ indicamos a relevância de referenciar a especificidade da formação de professores para a EPT no bojo do entendimento do lugar em que se concebe o lócus da universidade como privilegiado para formar o docente, que desenvolverá sua profissionalidade seja na educação básica (aqui incluída a EPT) ou no ensino superior (COSTA, 2012, p. 202).

Evidencia, portanto, a relevância de se promover a formação pedagógica dos professores da educação profissional na universidade, considerando as especificidades desta modalidade de educação, sob a premissa de que todo o professor deve conhecer o conteúdo da disciplina sob sua responsabilidade, bem como questionar, recriar, relacionar os diversos conhecimentos e efetivar um processo de iniciação científica com os alunos, incitando-os a buscar novos conhecimentos para antigos aprendizados. Considera, assim, que muitos dos problemas do ensino, decorrentes da formação inadequada dos professores, acabam por dificultar a aprendizagem dos alunos. E este aspecto pode ser superado mediante o desenvolvimento da dimensão pedagógica da formação do professor, que, por conseguinte, pode contribuir para o processo de integração das dimensões formativas da própria educação profissional em sua origem.

Enfatizando a complementaridade entre a formação inicial e a formação continuada, o trabalho de Urbanetz (2011) evidencia um processo de valorização do trabalho do professor da educação profissional que se concretiza, sobretudo, mediante a aquisição de conhecimentos técnicos da área de atuação e específicos da prática de sala de aula, permeados por elementos de natureza pedagógica.

$F_{4}$ : A pesquisa evidenciou que os professores entrevistados se constituem como docentes a partir da sua experiência de trabalho na engenharia. Ou seja, constituem-se a partir do conhecimento tácito, articulado ao conhecimento científico adquirido na graduação. Assim, a sua competência, reconhecida pelos alunos, resulta da capacidade de, pela experiência, articular teoria e prática no âmbito dos processos de trabalho a serem ensinados. Em resumo, ensinam a partir de sua experiência enquanto profissional da área específica (URBANETZ, 2011, p. 126-127).

O estudo sinaliza que o comprometimento com as questões do ensino e da educação surgem, naturalmente, da competência pedagógica do professor, enfatizando a necessidade de haver uma articulação destes conhecimentos com as diretrizes do mercado de trabalho e com a prática profissional em uma área específica (como engenheiro, por exemplo). Além de reconhecer a importância da formação em nível de licenciatura para o exercício da docência na educação profissional, sugere que os professores bacharéis da referida modalidade de educação sejam submetidos a esta formação de caráter pedagógico. 


\section{autêntica}

DOI https://doi.org/10.31639/rbpfp.v\%vi\%i.210

Oliveira (2011) defende a importância da participação do professor nos processos de planejamento do ensino, na construção dos planos de trabalho das disciplinas da educação profissional, bem como nos processos de decisão. Segundo o estudo, esta participação do professor viabiliza o desenvolvimento de práticas reflexivas e influencia o processo de constituição docente na medida em que promove a articulação entre teoria e prática e o diálogo entre as diversas disciplinas curriculares.

$\mathrm{F}_{5}$ : Torna-se necessário desfazer o pressuposto de que a formação pedagógica, no sentido de colocá-la em prática, não é papel do professor para levar a um saber fazer reflexivo, que seja entendido como autoformação. Assim como o currículo necessita ser viabilizado integrando teoria e prática, da mesma maneira a construção das formações de professores carece trabalhar com a indissociabilidade teoria-prática (OLIVEIRA, 2011, p. 96).

Portanto, para Oliveira (2011), o professor assume centralidade no processo de promover a articulação entre teoria e prática ao mesmo tempo em que esta articulação precisa ser contemplada na dimensão dos programas de formação promovidos com estes profissionais, assim como na dimensão do currículo de formação dos estudantes da educação profissional.

Martins (2011), por seu lado, ressalta a importância de o professor da educação profissional identificar-se com a sua formação inicial, pois este conhecimento constitui-se em alicerce da docência, caracterizando o seu trabalho docente voltado ao contexto do mercado de trabalho.

$F_{6}:[\ldots]$ a forte identificação com o conhecimento próprio da área de Nutrição, parece influenciar a relação com a docência, já que o ofício do professor envolve o saber do conteúdo relativo às suas áreas de formação. Em nosso olhar, essa condição é potencializada com a área de atuação, ou seja, o trabalho na educação profissional, que reflete um ensino aplicado ao contexto do mercado de trabalho. Assim, entendemos que a experiência profissional na área da Nutrição aponta um caminho de sustentação e segurança dessas professoras para atuar na educação e, especialmente, no ensino profissional (MARTINS, 2011, p. 120).

Ao focar as relações que se consolidam entre as experiências profissionais vivenciadas por profissionais da área da Nutrição e a sua atuação docente, o estudo mostra que os saberes específicos da área de atuação influenciam a prática docente, na medida em que dão suporte e segurança aos docentes para concretizar o ensino em sala de aula. Além disso, aponta à tomada de consciência dos docentes quanto ao reconhecimento da necessidade do domínio dos saberes pedagógicos basilares à prática docente, ponderando, inclusive, os impactos que as ausências destes podem ocasionar à aprendizagem dos alunos e à qualidade do trabalho docente.

$F_{7}:[\ldots]$ reconhecemos que a formação dessas docentes não prescinde de referências teóricas ligadas ao trabalho do professor propriamente, já que em suas trajetórias poucas foram as oportunidades de participação em espaços de formação. Mas, não somente nós reconhecemos, mas também as professoras consideram a necessidade e importância de uma qualificação na área educacional, além de indicarem enfaticamente a preocupação e o comprometimento com a aprendizagem dos alunos (MARTINS, 2011, p. 120).

Em síntese, o estudo de Martins (2011) aponta que o processo de constituição docente do professor da educação profissional se concretiza no âmbito da experiência cotidiana, na relação com os pares e a partir do aprimoramento das práticas pedagógicas. Neste sentido, considera que segurança na atuação docente está 


\section{autêntica}

DOI https://doi.org/10.31639/rbpfp.v\%vi\%i.210

diretamente relacionada ao conhecimento do professor em sua área de atuação, favorecendo uma prática pedagógica que vai além dos limites teóricos do ensino e que encontre sustentação na formação para o trabalho. Ou seja, para os professores participantes da pesquisa, a prática pedagógica oportuniza aos docentes da educação profissional ressignificar os saberes teóricos adquiridos na formação acadêmica. Além disso, a experiência cotidiana e a interação com os pares constituem-se em contexto para o desenvolvimento de saberes tácitos da docência na educação profissional.

Portanto, a categoria aqui discutida aponta para a um processo de formação docente que prioriza a articulação entre teoria e prática (CONTRERAS, 2012), tomando a prática cotidiana como contexto para ressignificação de saberes e desenvolvimento de saberes tácitos, considerando e valorizando a experiência profissional e os saberes técnicos de formação específica. Nesta perspectiva, os conhecimentos teóricos propositivos articulam-se aos conhecimentos da prática em um processo ressignificação de ambos. E neste processo, a teoria oferece ao professor perspectivas de análises para compreender os contextos históricos, sociais, culturais, organizacionais aos quais está inserido, ao tempo em que é oportunizado a compreender-se como profissional e compreender como se dá a atividade docente em um contexto específico, para nele intervir, transformando-o (PIMENTA e GHEDIN, 2005).

A perspectiva evidenciada nestes trabalhos está centrada na importância de oportunizar aos professores de educação profissional uma formação docente que valorize a relação entre teoria e prática, favorecendo uma prática reflexiva por parte destes professores. Esta perspectiva encontra aporte em Contreras (2012), na medida em que pressupõe uma concepção de professor como um profissional reflexivo e autônomo, cuja formação lhe permita intervir de forma crítica e consciente nos contextos da prática e nas situações em que as decisões emergem de processos complexos, ambíguos e conflituosos. Ao assumir este papel, o professor converge para um nível de autonomia docente que deve ser entendida como a independência intelectual e se justifica pela emancipação pessoal da autoridade e controle repressivo, da superação das dependências ideológicas ao questionar criticamente nossa concepção de ensino e da sociedade. Daí decorre o permanente exercício da crítica das condições materiais nas quais o ensino ocorre.

Podemos enfatizar, então, a necessidade e a urgência de superação do modelo de racionalidade instrumental pelo processo de emancipação e autonomia na formação do professor, bem como compreender que a formação pessoal e profissional se caracteriza como um devir permanente, envolvendo as experiências de formação - inicial e continuada - e as experiências no exercício da profissão, pois a profissão docente pressupõe características e conhecimentos que tornem o professor um profissional capaz de intervir de maneira ampla e coerente nas distintas situações do cotidiano escolar e que possa deixar marcas positivas na formação dos alunos (CASTANHO, 2001).

Assim, a constituição da profissionalidade docente no âmbito da educação profissional está centrada no desenvolvimento de saberes docentes que abarcam o professor como pessoa, a identidade profissional que se consolidam nesta modalidade de educação, as suas experiências de vida e histórias profissionais envolvendo as relações com os alunos e demais atores escolares (TARDIF, 2013). E este processo, pelas especificidades desta modalidade de educação, atribui relevância à dimensão prática, considerando-a como basilar as práticas de sala de aula, e atribui à dimensão pedagógica o importante papel de qualificar esta prática, promovendo, deste modo, a articulação entre teoria e prática.

Portanto, nesta perspectiva de formação pedagógica, a prática docente na educação profissional consiste em um processo que pressupõe mais do que um conjunto de procedimentos técnicos e sistemáticos de 


\section{autêntica}

DOI https://doi.org/10.31639/rbpfp.v\%vi\%i.210

transmissão de conhecimentos estanques. Consiste em um processo consciente e qualificado, que envolve dimensões epistemológicas, éticas e políticas e, ao mesmo tempo, implica em um compromisso com a sociedade mediante a finalidade de contribuir para a formação consciente e crítica do cidadão e do profissional que atua e interage no contexto social.

Relativamente a perspectiva formação profissional docente que se concretiza mediante a constituição profissional do professor e a prática pedagógica, manifestada nos trabalhos de Barbacovi (2011), Santos (2013), Martins (2011) e Urbanetz (2011), foram destacados aspectos relacionados à ênfase na dimensão prática da formação do professor da educação profissional e a importância da formação continuada para a melhoria das práticas de sala de aula.

Barbacovi (2011) afirma em seu estudo que a prática docente é o fator preponderante e determinante na constituição docente do professor de educação profissional. Reforça a relação entre a constituição profissional do professor e a atividade pedagógica por ele desenvolvida, atividade esta por meio da qual concretiza-se o processo de formação contínua do professor.

$F_{8}$ : Os dados apontaram que o que mais interfere na constituição docente é a prática docente como, aliás, afirmaram também a maioria dos respondentes [...]. Não se trata de qualquer prática. A prática docente dotada dos seus sentidos intrínsecos - relações simbióticas entre teoria e prática - é que dá sustentação e firmeza ao próprio processo de formação docente que é contínuo e se faz para além dos cursos formais institucionalmente apresentados (BARBACOVI, 2011, p. 226).

Os elementos destacados corroboram a ideia da formação contínua como um processo de desenvolvimento de conhecimentos da prática pedagógica em sala de aula, especialmente voltados à educação profissional, que se concretiza mediante os significados atribuídos pelos professores aos saberes relativos à tais práticas no contexto das suas atividades sociais e profissionais. E esta formação precisa levar o professor a apropriar-se de conhecimentos que viabilizem práticas reflexivas e adequadas à preparação para o trabalho dos alunos. Reforça que a constituição docente do professor de educação profissional é imbuída muito mais pela ação na prática que executa do que, necessariamente, pela aquisição de saberes pedagógicos mediante cursos formais ao qual foi submetido. E tal processo oferece sustentação e firmeza ao próprio processo de tornar-se professor a partir da formação docente na dimensão continuada, transcendendo os percursos formativos institucionalmente ofertados.

Santos (2013) aponta para a importância da formação continuada, concretizada em serviço, a partir da experiência da prática docente e das interações dos professores com seus pares na educação profissional. Argumenta que esta formação não acontece apenas em processos formais como cursos de licenciatura, pós-graduação ou de formação continuada, mas também em eventos, congressos, seminários ou outro evento que possa promover o debate do desenvolvimento do trabalho docente.

$F_{9}$ : A pesquisa aponta para um novo perfil de professor da Educação Profissional, que se requer reflexivo, que se reconhece com saberes, [...] compreendendo que é parte de um contexto sócio-histórico e nele constrói sua singularidade (SANTOS, 2013, p. 142).

Este trabalho evidencia, portanto, as interferências exercidas pelas condições de trabalho do professor e pelo contexto social, no qual está inserido, na sua constituição docente. Constata, assim, que um novo perfil 


\section{autêntica}

DOI https://doi.org/10.31639/rbpfp.v\%vi\%i.210

profissional docente está emergindo no âmbito da educação profissional, o qual revela-se reflexivo e necessita dispor de conhecimentos profissionais distintos para atuar nesta modalidade de educação.

Nesta perspectiva de formação pedagógica, a profissionalidade docente constitui-se, especialmente, no contexto na prática cotidiana de sala de aula do professor, compondo-se por aquilo que é inerente a ação docente, incluindo o conjunto de comportamentos, conhecimentos, destrezas, atitudes e valores que constituem a especificidade de ser professor (SACRISTÁN, 1995) nesta modalidade de educação, caracterizada por suas particularidades e ambiguidades históricas, sociais e culturais.

Neste sentido, defende um perfil profissional do professor da educação profissional que se constitui em um contexto sócio histórico, considerando as suas singularidades e especificidades, reflexivo e alicerçado em saberes. Evidencia que a tomada de consciência por parte do professor é fundamental para que o processo de desenvolvimento profissional aconteça e que a busca pela formação não deve restringir-se apenas às ações ofertadas pela instituição de ensino, na qual o professor trabalha. Sugere, assim, uma visão de formação docente pautada em processos reflexivos e de compreensão do papel assumido pelo professor na educação profissional, considerando o contexto social no qual está inserido e as finalidades desta modalidade educativa. E esta formação pode promover o desenvolvimento profissional do professor de uma maneira ampla, contemplando suas singularidades.

Martins (2011) evidencia os processos que interferem na constituição profissional do professor na educação profissional, destacando que para os depoentes, o professor possui uma habilidade individual própria para exercer a docência, e que a constituição docente se fundamenta, sobretudo, nas práticas de outros professores.

$F_{10}:[\ldots]$ as professoras, ao afirmarem o reconhecimento de que carregam uma habilidade própria e individual para exercer a docência, de que suas referências teórico-metodológicas estão fundamentadas nas práticas de ex-professores e colegas professores, de que ainda suas experiências no campo da Nutrição Ihe conferem argumentos e sustentação para suas dinâmicas de sala, e de que seus desempenhos, abordagens e intervenções educativas são aprimoradas ao longo de suas carreiras aprendendo a ensinar, ensinando, revelam processos de constituição como docentes (MARTINS, 2011, p. 120-121).

O estudo revela, portanto, uma concepção de que a prática pedagógica em sala de aula tem na dimensão do conhecimento prático, específico do campo de atuação, a sua principal componente. E neste viés, predomina a perspectiva de que a docência na educação profissional se sustenta na prática cotidiana do professor, sofrendo algumas interferências em face à relação com colegas da área de atuação, a quais favorecem o aprimoramento das práticas pedagógicas. E, portanto, a dimensão pedagógica da formação docente não é importante e sequer necessária.

Assim, esta profissionalidade é marcada por elementos de naturezas diversas que definem a prática docente, levando-se em conta as exigências do trabalho educativo e os valores e pretensões impregnados neste trabalho e por ele desenvolvido (CONTRERAS, 2012), elementos estes que são próprios desta modalidade de educação. Além disso, a perspectiva de formação pedagógica docente aqui discutida sugeriu, em alguma medida, a emergência de um perfil profissional docente reflexivo e autônomo, perfil este que se constitui em um contexto sócio histórico, considerando as suas singularidades e especificidades, e alicerçado em saberes (CONTRERAS, 2012), cujas especificidades da educação profissional atribuem-lhe papel determinante na formação de um profissional também crítico e autônomo. 


\section{autêntica}

DOI https://doi.org/10.31639/rbpfp.v\%vi\%i.210

Por este entendimento, a formação docente na educação profissional é constituída e imbuída pela ação prática concretizada pelo professor e menos pelos cursos a que se teve acesso - embora é possível afirmar que os cursos frequentados ajudaram a consolidar essa prática, pois esta ação não se faz isoladamente. Esta concepção de formação docente coloca em relevo importantes concepções e tendências que tem pautado os processos de formação docente no Brasil, contemplando de uma maneira geral, as especificidades de diferentes níveis e modalidade de ensino, entre elas a educação profissional.

Portanto, o professor da educação profissional constitui-se professor a partir dos significados sociais da profissão, da reafirmação de práticas e desenvolve-se e adapta-se ao contexto sócio-político-histórico em que o professor está inserido (PIMENTA, 1999), mas também pela reafirmação das práticas histórica e culturalmente instituídas nesta modalidade educativa e que permanecem significativas.

Compreendemos, assim, que as dimensões que constituem o exercício docente estão fortemente articuladas a história de vida dos professores. Tais dimensões indicam os significados atribuídos pelos professores aos acontecimentos, experiências e aprendizagens que perpassam os caminhos até a tomada de decisão pela docência. Indicam, também, a constituição da profissionalidade docente mediante o confronto entre as teorias e as práticas, a análise sistemática das práticas à luz das teorias existentes e a proposição de novas teorias. 


\section{autêntica}

DOI https://doi.org/10.31639/rbpfp.v\%vi\%i.210

\section{CONSIDERAÇÕES FINAIS}

A análise sobre os dez trabalhos (dissertações e teses) revelou uma fragilidade quanto à formação docente dos professores de educação profissional, na medida em que as pesquisas apontaram que a maioria dos docentes atuantes nesta modalidade educativa não possui formação inicial com bases pedagógicas, e que os programas de formação continuada também são escassos. Desta forma, os professores, bem como os sujeitos envolvidos no processo de ensino buscam alternativas próprias na tentativa de diminuir a distância pedagógica presente no ensino da educação profissional que é constituída, sobretudo, por profissionais oriundos, em sua maioria, de cursos relacionados à área de tecnologia, como engenharias.

Relativamente as ações formativas promovidas no contexto das instituições de educação profissional, os resultados dos estudos mostram que tais ações, em geral, não estão em sintonia com as necessidades do público atendido e com as finalidades desta modalidade de educação. Uma das caraterísticas observadas na dimensão da docência na educação profissional é a reprodução de uma prática docente fragmentada e pragmática, imbuída de um discurso de manutenção do sistema capitalista em prol de uma economia neoliberal.

Os professores da educação profissional, em sua maioria formados como bacharéis, desenvolvem o trabalho docente pautado na racionalidade técnica e, de acordo com os depoimentos dos entrevistados, entendem como natural o fato de apenas lecionarem e não produzirem, de fato, o conhecimento e as estratégias que permeiam o ensino da sua disciplina. Este aspecto é reforçado pelo fato de que o professor da educação profissional é influenciado e conformado pela mesma ideologia que predomina no mundo do trabalho contemporâneo, tendendo a desenvolver sua atividade docente com base, sobretudo, em saberes técnicos e específicos de sua atividade profissional adquirido na formação inicial universitária.

Em síntese, a análise que realizamos evidenciou que no âmbito da educação profissional os processos de desenvolvimento da profissionalidade e de constituição docente são influenciados pelos percursos formativos dos professores que atuam nesta modalidade educativa e, também, pelas concepções, crenças, práticas e valores instituídos nas instituições e cursos em que atuam. Assim, de maneira geral, os professores que possuem alguma formação de natureza pedagógica, seja em nível de graduação universitária ou mediante a frequência em cursos de complementação formativa ou ações de formação continuada ofertadas pelas instituições em que atuam, atribuem relevância a esta dimensão da formação docente, concebendo-a essencial para a concretização da relação teoria-prática. Em contrapartida, aqueles professores com formação técnica, em nível de bacharelado ou algum outro curso profissionalizante e sem formação de natureza pedagógica, consideram que o conhecimento específico da profissão que exercem é suficiente para o exercício da docência na educação profissional. Acrescentam, ainda, que o aprimoramento da prática pedagógica de sala de aula se dá na medida em que o professor consegue relacionar este conhecimento com o mundo do trabalho e, portanto, a constituição docente se concretiza no contexto da prática cotidiana.

Portanto, nosso estudo aponta para a necessidade de valorização e promoção dos processos reflexivos sobre a prática docente, pelos próprios docentes, relacionando a teoria e a prática no trabalho docente, como forma de promover, também, práticas reflexivas e emancipadoras com os alunos em sala de aula. O professor da educação profissional precisa assumir a responsabilidade de seu papel no contexto educacional e levantar questões sobre o que e como ensina, conhecendo os propósitos e as condições escolares, envolvendo a sociedade numa educação de uma classe de intelectuais que rompam com os paradigmas que balizam a melhoria da educação.

Mediante estes resultados, vislumbramos a urgência de pensar numa política de formação inicial e continuada quanto à formação docente do professor de educação profissional. Também antevemos a urgência de se desenvolver, no interior das instituições, momentos efetivos de trabalho coletivo entre os professores, pois, desse trabalho articulado entre eles e seus saberes, é que poderá surgir de fato e de modo contínuo, a prática reflexiva, sendo essa a condição de superação dos desafios também contínuos vividos na profissão. 


\section{autêntica}

DOI https://doi.org/10.31639/rbpfp.v\%vi\%i.210

\section{REFERÊNCIAS}

ANDRÉ, M. A constituição da profissionalidade docente: os efeitos do campo de tensão do contexto escolar sobre os professores. Reunião Nacional da ANPEd, 36., Anais... Goiânia, 2013. Disponível em: <http://36reuniao. anped.org.br/pdfs_trabalhos_aprovados/gt08_trabalhos_pdfs/gt08_2640>. Acesso em: 30 jan. 2015.

ARAÚJO, W.P. A formação docente para a educação profissional e tecnológica no IFNMG-Campus Januária. 2014. 197 f. Dissertação (Mestrado em Educação) - UNB. Brasília, 2014.

BARBACOVI, L.J. O Professor da educação profissional e a conectividade orgânica entre formação e prática docente: um estudo sobre o IFET Sudeste de Minas Gerais. 2011. 292 f. Tese (Doutorado em Educação) UFMG. Belo Horizonte, 2011.

BARDIN, L. Análise de conteúdo. Lisboa: Edições 70, 1977.

BRASIL. Ministério da Educação. Conselho Nacional de Educação. Resolução CNE/CEB, n. ${ }^{\circ} 3$, de 26 de junho 1998. Diário Oficial da União, 5 ago. 1998. Brasília. Disponível em: <http://portal.mec.gov.br/cne/arquivos/ pdf/1998/rceb03_98.pdf>. Acesso em: 12 jun. 2015.

BRASIL. Ministério da Educação. Lei n. 9.394, de 29 de dezembro de 1996. Diário Oficial da União, 23 dez. 1996. Brasília. Disponível em: <http://www.planalto.gov.br/ccivil_03/leis/l9394.htm> . Acesso em: 02 abr. 2015

CASTANHO, M.E. Sobre professores marcantes. In: CASTANHO, S. (Org.). Temas e textos em metodologia do ensino superior. Campinas: Papirus, 2001, p. 29-35.

CONTRERAS, J. Autonomia de professores. 2. ed. São Paulo. Cortez: 2012.

COSTA, M.A. da. Políticas de formação de professores para a educação profissional e tecnológica: cenários contemporâneos. 2012. 231 f. Tese (Doutorado em Educação) - UFU. Uberlândia, 2012.

DUBAR, C. A socialização: construção das identidades sociais e profissionais. SP: Martins Fontes, 2005.

ERICKSON, F. Qualitative methods in research on teaching. In:WITTROCK, M. C. (Ed.) Handbook of Research on teaching. 3rd ed. New York, NY: Macmillan, 1896. p.119-161

ESQUINSANI, R.S.S. O trabalho docente na educação brasileira: contextos e expectativas. In: DURLI, Z.; SILVA, R. R. da; RIBEIRO, V.N. da S. (Orgs.). Formação docente em perspectiva. Passo Fundo: Editora Universidade de Passo Fundo, 2012.

HOBOLD, M.S. A constituição da profissionalidade docente: um estudo com professores de educação profissional. Contrapontos, Itajaí, v. 4, n. 2, p. 269-282, mai./ago. 2004.

IANNI, O. O cidadão do mundo. In: SANFELICE, J.L.; SAVIANI, D.; LOMBARDI, J.C. (Org.). Capitalismo, trabalho e educação. Campinas, São Paulo: Autores Associados, Histedbr, 2005.

KUENZER, A.Z. O Ensino Médio agora é para a vida: entre o pretendido, o dito e o feito. In: Educação \& Sociedade. n. 70. Campinas: CEDES, p. 15-39, abr./2000.

KUENZER, A.Z. Ensino médio: Construindo uma proposta para os que vivem do trabalho. 5. ed. São Paulo: Cortez, 2007. 


\section{autêntica}

DOI https://doi.org/10.31639/rbpfp.v\%vi\%i.210

LABAREE, D.F. On the Nature of Teaching and Teacher Education: Difficult Practices That Look Easy. Journal of Teacher Education, v. 51, n. 3. p. 228-233, mai./jun. 2000.

LIMA, F.B.G de. A formação de professores nos institutos federais de educação, ciência e tecnologia: um estudo da concepção política. 2013. 282 f. Dissertação (Mestrado em Educação) - UNB. Brasília, 2012.

LÜDKE, M.; ANDRÉ, M. Pesquisa em educação: abordagens qualitativas. São Paulo: EPU, 2003.

MACHADO, L.R. de S. Diferenciais inovadores na formação de professores para a educação profissional. Revista Brasileira de Educação Profissional e Tecnológica. v. 1, n. 1, Brasília: MEC, SETEC, p. 8-22, jun./2008.

MACHADO, L.R. O desafio da formação dos professores para a EPT e PROEJA. Revista Educação e Sociedade. Campinas. v. 32, n. 116, p. 689-704. jul./set. 2011.

MANFREDI, S.M. Educação profissional no Brasil. São Paulo: Cortez, 2002.

MARCELO GARCÍA, C. Pesquisa sobre a formação de professores: O conhecimento sobre aprender a ensinar. Revista Brasileira de Educação, n. 9, p. 51-75, 1998.

MARCELO GARCÍA, C. Formação inicial de professores. In: GARCIA, C.M. (Org.). Formação de professores para uma mudança educativa. Lisboa: Porto, 1999. cap. 2, p. 69-108.

MARCELO GARCÍA, C. Desenvolvimento Profissional: passado e futuro. Sísifo-Revista das ciências da educação, n. 8, p. 7-22, jan./abr. 2009.

MARTINS, L.A. Trajetórias de constituição da docência na educação profissional. 2011. 130 f. Dissertação (Mestrado em Educação) - UNICAMP. Campinas, 2011.

MORGADO, José Carlos. Identidade e profissionalidade docente: sentidos e (im) possibilidades. Revista Ensaio: Avaliação e Políticas Públicas em Educação, v. 19, n. 73, p. 793-812, 2011.

NÓVOA, A. O passado e o presente dos professores. In: NÓVOA, A. (Org.). Profissão professor. Porto: Porto Editora, 1995. p. 13-34.

NÓVOA, A. Os professores na virada do milênio: do excesso dos discursos à pobreza das práticas. Educação e Pesquisa, São Paulo, v. 25, p. 11-20, jan./jun. 1999.

Para uma formação de professores construída dentro da profissão. Revista Educación, Madrid, n. 350, p. 203-218, set./dez. 2009.

NÓVOA, A. Nada substitui um bom professor: propostas para uma revolução no campo da formação de professores. In: GATTI, B. A. (Org.). Por uma política nacional de formação de professores. São Paulo: Editora Unesp, 2013, p. 199-210.

OGLIARI, C.R.N. Concepção de formação inicial de professores para a educação profissional de nível médio: um aspecto da história da educação no Estado do Paraná. 2006. 166 f. Dissertação (Mestrado em Educação) - PUC/PR. Curitiba, 2006.

OLIVEIRA, M.A.M. O ensino de filosofia no 2.․ Grau da escola brasileira: um percurso histórico, até a realidade mineira dos anos 80. 1993. Dissertação (Mestrado do Programa de Pós-graduação em Educação) - Pontifícia Universidade Católica de São Paulo, São Paulo, 1993. 


\section{autêntica}

DOI https://doi.org/10.31639/rbpfp.v\%vi\%i.210

OLIVEIRA, M.R.N.S. de. A formação de professores para a educação profissional. In: DALBEN, A.L.; DINIZ, J.; LEAL, L.; SANTOS, L. (Orgs.). Coleção Didática e Prática de Ensino. Belo Horizonte: Autêntica Editora, 2010, p. 455-478.

OLIVEIRA, N.P. Formação continuada de professores e o desenvolvimento de currículos integrados na educação profissional e tecnológica. 2011. 124 f. Dissertação (Mestrado em Educação) - UNICAMP. Campinas, 2011.

OLIVEIRA, R. de. A (des)qualificação da educação profissional brasileira. São Paulo: Cortez, 2003

OLIVEIRA, R. de. A Reforma da Educação Profissional nos Anos 90. In: BATISTA, E.L.; MÜLLER, M.T. (Orgs.). A Educação Profissional no Brasil: história, desafios e perspectivas para o século XXI. Campinas, SP: Alínea, 2013. p. 219-234.

ORSO, A.P.G.; MIGUEL, M.E.B. História das políticas educacionais de formação de professores dos cursos técnicos em nível médio. Revista Intersaberes, Curitiba, a. 6, n. 12, 2011, p. 90-108.

PENA, G.A. de C. Formação docente e aprendizagem da docência: um olhar sobre a educação profissional. Revista educação em perspectiva, Viçosa. v. 2, n. 1, 2011, p. 98- 118.

PIMENTA, S.G. Formação de professores: Identidade e saberes da docência. In: PIMENTA, S.G. (Org.), Saberes pedagógicos e atividade docente. São Paulo: Cortez, 1999.

PIMENTA, S.G, GHEDIN, E. (Orgs.). Professor reflexivo no Brasil: gênese e crítica de um conceito. 3. ed. São Paulo: Cortez, 2005.

PINTO, L.M de C da S. A constituição do professor pelo trabalho docente na educação profissional: o caso do IFMT - Campus Cuiabá - Octayde Jorge da Silva. 229 f. Tese (Doutorado em Educação). UFRGS. Porto Alegre, 2014.

POPKEWITZ, T.S. Sociología política de la reforma educativa. Madri: Mormata, 1991.

REIS MONTEIRO, A. Qualidade, profissionalidade e deontologia na educação. In: Coleção Panorama, n. 9. Portugal: Porto Editora, 2008.

ROLDÃO, M.C. Profissionalidade docente em análise: especificidades dos ensinos superior e não superior. Nuances: estudos sobre educação. v. 12, n. ${ }^{\circ} .13$, jan./dez. 2005, p. 105-126. Disponível em: <http://revista. fct.unesp.br/index.php/Nuances/article/viewFile/1692/1601 >. Acesso em: 29 fev.2016.

SACRISTÁN, J.G. Consciência e acção sobre a prática como libertação profissional dos professores. In:TARDIF, M. Saberes docentes e formação profissional. 15. ed. Petrópolis, RJ: Vozes, 2013.

TARDIF, M.; LESSARD, C. O trabalho docente: elementos para uma teoria da docência como profissão de interações humanas. 8. ed. Petrópolis: Vozes, 2013. 